Dhaka Univ. J. Biol. Sci. 22(1): 9-20, 2013 (January)

\title{
EFFECTS OF HIGH TEMPERATURE ON THE EGGS OF AEDES AEGYPTI (L.) AND SUBSEQUENT STAGES DEVELOPED THERE FROM
}

\author{
Humayun Reza KHAN* and Farjana RaHman \\ Department of Zoology, University of Dhaka, Dhaka-1000, Bangladesh
}

Keywords: Temperature, Aedes agypti, Mosquito, Eggs, Hatching, Mortality, Fecundity

\begin{abstract}
The eggs laid by the emerged Aedes aegypti (L.) (Diptera: Culicidae) females were treated with high temperature at $35^{\circ} \mathrm{C}$ at different exposure periods, viz., half an hour, one, two, four, eight and 24 hours, separately along with their control. At different exposure periods at $35^{\circ} \mathrm{C}$ and control - the percentage of egg hatching ranged from 59 to 97; larval and pupal mortality ranged from zero to 12 and 3 to 14 per cent, respectively. Larval and pupal periods were 76 to 115 and 33 to 42 hours, respectively. Lengths of $2^{\text {nd }}, 3^{\text {rd }}, 4^{\text {th }}$ instars were 3.615 to 4.518 ; 5.575 to 6.455 and 7.13 to $7.62 \mathrm{~mm}$, respectively. Mean diameters of the head capsule of $1^{\text {st }}, 2^{\text {nd }}, 3^{\text {rd }}$ and $4^{\text {th }}$ instar larvae were 0.243 to $0.336,0.387$ to $0.476,0.644$ to 0.695 and 0.723 to $0.907 \mathrm{~mm}$, respectively. Length of the cephalothorax of pupae was 1.49 to 1.907 $\mathrm{mm}$. Body lengths of male and female adults were 2.9 to 3.00 and 3.33 to $3.51 \mathrm{~mm}$, respectively.
\end{abstract}

\section{Introduction}

Aedes aegypti (L.) (Diptera: Culicidae) is a dangerous mosquito species. It is found in Dhaka city ${ }^{(1-4)}$. It is suspected to transmit human diseases in the city ${ }^{(5)}$ and plays a role in the transmission of diseases like dengue, hemorrhagic fever, yellow fever(6). The people of the city are threatened by this mosquito species. During March-August, 2000, Bangladesh witnessed a large-scale outbreak of dengue fever mainly in the urban areas of the country. Aedes aegypti has not been reported from the rural areas of Bangladesh(7). One possible reason might be due to the fact that this mosquito species prefer artificial containers to natural containers, and its breeding containers are readily and largely available in the urban areas.

Aedes aegypti is exclusively container breeder. Its immature stages are found in containers with water and the most frequently encountered artificial and natural breeding site were: used tyres, discarded tins, plastic containers, abandoned car parts, brick holes, dead leaves on ground, coconut shell, flower vases, tree holes and rock pools ${ }^{(8,9)}$. Adult mosquitoes usually stay at bushes around houses, dark corners of room, storehouse, and back side of furniture. Most of them come out to feed at dawn and dusk.

\footnotetext{
*Author for correspondence: <hrkha@hotmail.com>.
} 
Temperature has an impact upon insects in various ways. The extremes of temperature limit insect activities both in space and time. Their rates of metabolism and consequently those of growth, reproduction and general behaviour are largely controlled by temperature. The most important factors in the environment which influence the physiology of insects are temperature and humidity(10). The higher temperature has a harmful influence on the development of insect(11). The optimum temperature for the insect species is generally taken to be $28^{\circ} \mathrm{C}$; any increase above this appears to be increasingly unfavourable, and over $40^{\circ} \mathrm{C}$ it is quickly fatal and insects die from the effects of heat ${ }^{(12)}$. The effects of temperature on various stages of mosquito were studied by Hagstrum and Workman(13), Nayar(14), Dakshinamurty and Sharma(15).

The present paper deals with the effects of high temperature on the eggs of Ae. aegypti and the stages developed there from after hatching. The following aspects were observed after the eggs were exposed to high temperature in different exposure durations: the hatching efficiency of the eggs, the mortality rates of the larvae and the pupae; the durations of the larval and pupal stages; morphometry of some external body parts; and the fecundity of the female adults emerged.

\section{Materials and Methods}

The larvae of Ae. aegypti were collected from the earthen pots and aquaria placed in the Zoological garden, Curzon Hall campus, University of Dhaka. The larvae were collected with the help of a large dropper. The collected larvae were kept in a clean beaker and brought to the laboratory. They were then washed gently in tap water for several times to clean those from impurities. The larvae were then transferred to another beaker containing clean water. Ground glucose biscuits were provided the larvae as their food. The collected larvae were placed on slides within a few drops of water, examined under a compound microscope and identified following service ${ }^{(16)}$. The rearing of the mosquito and heat-experiment was carried out at an ambient environment (temperature $28 \pm 4^{\circ} \mathrm{C}$ and $70-80 \% \mathrm{RH}$ ) of the Entomological laboratory in the Department of Zoology, University of Dhaka.

The collected larvae were kept in a plastic bowl containing tap water and provided with ground biscuits as their foods. The larvae were transferred from one bowl to another, whenever necessary, with the help of a large dropper. The water was changed and ground biscuits were provided daily. Similar procedure was followed to rear the subsequent $2^{\text {nd }}, 3^{\text {rd }}$ and $4^{\text {th }}$ instar larvae.

The $4^{\text {th }}$ instar larvae moulted into pupae, which is a non-feeding stage in the life cycle of mosquito. The pupae were separated daily from the larval bowl with the use of a dropper and kept them in a plastic bowl which was previously filled with tap water. Since pupae do not take any food ${ }^{(17)}$, no food was, therefore, supplied to them. The plastic 
bowl with the pupae was kept in a mosquito rearing cage for the emergence of adult mosquito.

After emergence inside the cage, the adults were provided with $10 \%$ glucose solution daily as their food. The glucose solution was soaked in a cotton wad and placed it on a Petri dish, which was then kept inside the cage. The male mosquito only takes glucose solution as food throughout their life time. For the first two or three days of emergence, the females were also fed with the glucose solution.

Blood feeding is required for the nourishment and maturation of the eggs of the mosquito. From the $3^{\text {rd }}$ day after emergence, the adult female mosquitoes were allowed to feed on blood meal from a pigeon. The feather was removed from the breast region of the pigeon and kept in a tight small iron cage which could easily be placed inside the rearing cage. The blood feeding was initiated on the $4^{\text {th }}$ day after adult emergence and continued as long as the females were alive. After taking the blood meal, the abdomen of the females became large and reddish.

After taking blood meal, the females mated with the males. A plastic bowl containing tap water was taken and a filter paper strip was placed around the rim of the water in order that half of the paper was emerged in it. The bowl was then placed inside the rearing cage for the females to oviposit. The eggs were laid singly on the filter paper, abundantly a little bit above the water edge; sometimes the females laid eggs on the water surface singly. The number of eggs laid per female was recorded. The eggs containing filter paper were removed and left at room environment for five - seven days for drying. A drought condition is required for the maturation and development of the eggs of Ae. aegypti(17).

After desiccation, the eggs were dipped into tap water in a plastic bowl. When flooded with water, the eggs were hatched within a few minutes. The larvae were then reared again following the above procedure to obtain a continuous supply of adequate larvae for the experiment.

Only the healthy eggs were selected for temperature treatment. The eggs of $A e$. aegypti in a group of 50 in each of three replicates were used for this experiment. The eggs were exposed to $35^{\circ} \mathrm{C}$ in an incubator (SLI-600L, Japan) for half an hour, one, two, four, eight and 24 hours, separately. A control treatment of three replicates was also taken in which the eggs were not treated with temperature.

Six Petri dishes with filter paper had been kept in an incubator at $35^{\circ} \mathrm{C}$ for 24 hours before the heat-treatment began. Three strips of filter paper with 50 eggs of Ae. aegypti each, were then placed on each Petri dish. For each of the above mentioned exposure treatment, one Petri dish was taken out of the incubator and kept it at room temperature and humidity for five minute for cooling. The three strips with eggs were then dipped into the tap water contained in three plastic bowls in an ambient laboratory condition. The eggs were immersed in the water for 24 hours. The number of first instar larvae 
hatched in 24 hours in the water. The same procedure was followed for all exposure periods, i.e. half an hour, one, two, four, eight and 24 hours, separately. The data were recorded on the following aspects: Hatching efficiency of the temperature treated eggs; Larval mortality; Pupal mortality; Larval duration; Pupal duration; Measurements of larval length and its head capsule; Measurements of pupal length and its cephalothorax; Size of male and female adults emerged and fecundity.

The data were reported as arithmetic mean \pm standard deviation (Sd). ANOVA was applied on the data to assess the treatment effect. When F-values indicated significant difference, DMRT was employed to discern specific difference among the treatments. All the statistical analyses were done on a computer using statistical software package SPSS. The corrected mortality was done by using Abbot's $^{(18)}$ formula whenever necessary. The formula was $[(\mathrm{Po}-\mathrm{Pc}) /(100-\mathrm{Pc})] \times 100$, where $\mathrm{Po}=$ Per cent mortality observed and $\mathrm{Pc}$ $=$ Per cent mortality in control.

\section{Results and Discussion}

The eggs of Ae. aegypti hatched showed significant difference $(\mathrm{F}=7.358, \mathrm{p}<0.05)$ among different exposure periods and control (Table 1). The high percentage of hatching occurred in control (96.66) and the lowest in 24 hour heat exposure (59.34). A trend of gradual reduction of egg hatching was observed from control to 24 hour of exposure treatment. These results indicate that the temperature at $35^{\circ} \mathrm{C}$ with different exposures had an impact on the egg hatching of the mosquito species. In the present findings, egg mortality increased gradually with increasing exposure periods at high temperature $\left(35^{\circ} \mathrm{C}\right)$ which is in conformity with the observations that greater temperatures resulted in greater egg mortality ${ }^{(19)}$. About $28 \%$ of the egg mortality of Ae. aegypti was reported at $35^{\circ} \mathrm{C}(20)$.

The mortality of the larvae and pupae of Ae. aegypti is shown in Tables 2 and 3, respectively. Larval mortality in control was corrected by following Abbot's formula. In the present findings high temperature and different exposures showed insignificant effects $[\mathrm{F}=1.15173, \mathrm{p}>0.05$ in case of larvae (Table 2) and $\mathrm{F}=0.649446, \mathrm{p}>0.05$ in case of pupae (Table 3)] on larval and pupal mortalities.

Temperature has, however, some effects on the larval and pupal mortality of Ae. aegypti and the sensitiveness of the larvae of the mosquito increased with later instars and pupa, the second instar congregating between 23 and $32^{\circ} \mathrm{C}$ whilst later stages and pupa did so between 28 and $32^{\circ} \mathrm{C}^{(21)}$. 
Table 1. Hatching efficiency of the eggs of Ae. aegypti treated at $35^{\circ} \mathrm{C}$ in different exposure periods and control in an ambient condition of the laboratory (at $28 \pm 4^{\circ} \mathrm{C}$ and $\left.80 \% \mathrm{RH}\right)$.

\begin{tabular}{lccccc}
\hline $\begin{array}{l}\text { Exposure } \\
\text { period per (hrs) }\end{array}$ & $\begin{array}{c}\text { No. of eggs } \\
\text { replicate }\end{array}$ & $\begin{array}{c}\text { No. of } \\
\text { replicate }\end{array}$ & $\begin{array}{c}\text { No. of larvae } \\
\text { hatched (mean } \pm \text { SD) }\end{array}$ & $\begin{array}{c}\text { No. of larvae } \\
\text { hatched replicate (\%) }\end{array}$ & F-value \\
\hline Control & 50 & 3 & $48.33 \pm 1.15^{\mathrm{a}}$ & 96.66 & 88.00 \\
0.5 & 50 & 3 & $44.00 \pm 2.645^{\mathrm{ab}}$ & 80.66 & \\
1 & 50 & 3 & $40.33 \pm 3.511^{\mathrm{b}}$ & 83.34 & $7.3588^{*}$ \\
2 & 50 & 3 & $41.67 \pm 2.516^{\mathrm{ab}}$ & 76.66 & \\
4 & 50 & 3 & $38.33 \pm 4.618^{\mathrm{bc}}$ & 65.34 & \\
8 & 50 & 3 & $32.67 \pm 4.509^{\mathrm{ab}}$ & 59.34 & \\
24 & 50 & 3 & $29.67 \pm 7.023^{\mathrm{d}}$ & \\
\hline
\end{tabular}

*Significant at $5 \%$ level $(\mathrm{F}=7.3588, \mathrm{p}<0.05)$; same letters in the column showing insignificant difference at $5 \%$ level in DMRT.

Table 2. Mortality of the larvae of Ae. aegypti hatched from the eggs treated at $35^{\circ} \mathrm{C}$ in different exposure periods and control in an ambient condition of the laboratory $\left(\right.$ at $28 \pm 4^{\circ} \mathrm{C}$ and $80 \%$ RH).

\begin{tabular}{lcccccc}
\hline $\begin{array}{l}\text { Exposure } \\
\text { period } \\
(\mathrm{hrs})\end{array}$ & $\begin{array}{c}\text { Total } \\
\text { no. of } \\
\text { larvae } \\
\text { hatched }\end{array}$ & $\begin{array}{c}\text { Total no. } \\
\text { of larvae } \\
\text { died }\end{array}$ & $\begin{array}{c}\text { Number of } \\
\text { larvae died } \\
(\text { mean } \pm \text { SD) } \\
(\%)\end{array}$ & $\begin{array}{c}\text { Mean } \\
\text { larval } \\
\text { mortality }\end{array}$ & $\begin{array}{c}\text { Corrected } \\
\text { mortality } \\
(\%)\end{array}$ & F value \\
\hline Control & 145 & 8 & $2.66 \pm 2.081$ & 5.22 & 0.0 & \\
0.5 & 132 & 22 & $7.33 \pm 3.214$ & 14.66 & 9.855 & \\
1 & 121 & 21 & $7.00 \pm 3.00$ & 14.00 & 9.158 & \\
2 & 125 & 25 & $8.33 \pm 4.163$ & 16.66 & 11.967 & 1.15173 \\
4 & 115 & 30 & $10.00 \pm 4.582$ & 20.00 & 15.495 & \\
8 & 98 & 21 & $7.00 \pm 5.291$ & 14.00 & 9.158 & \\
24 & 89 & 18 & $6.00 \pm 1.732$ & 12.00 & 7.045 & \\
\hline
\end{tabular}

Insignificant at $5 \%$ level $(\mathrm{F}=1.151732, \mathrm{p}>0.05)$; Larval mortality was corrected by following Abbott's formula.

The duration of larval and pupal periods as a result of high temperature at $35^{\circ} \mathrm{C}$ for various exposure periods and control was observed significantly $(F=64.44, p<0.05$ in case of larvae and $\mathrm{F}=30.0153, \mathrm{p}<0.05$ in case of pupae, Table 4). The highest duration was observed in control (viz., 114.6 hours in larvae and 41.8 hours in pupae) and gradually decreased as the temperature exposure periods increased (viz., 87.4, 85.5, 83.0, 81.6, 80.5, and 76.4 hours, respectively of larval duration and 40.4, 39.6, 38.9, 37.1, 35.2, and 33.1 hours, respectively of pupal duration (Table 4). 
At $27^{\circ} \mathrm{C}$ the duration of the complete larval period of Ae. aegypti was found seven days (168 hours) ${ }^{(22)}$ and at $23^{\circ} \mathrm{C}$ the complete duration of the larval period of the mosquito species was nine days (216 days) $)^{(23)}$. At $22^{\circ} \mathrm{C}$ the duration of the pupal stage of Ae. aeypti required three - four days (72 - 96 hours) ${ }^{(24)}$. Age of pupation increased as temperature decreased from 30 to $27^{\circ} \mathrm{C}$ (25). In the laboratory at $23^{\circ} \mathrm{C}$, the larval development time of Ae. albifasciatus was around nine days (216 hours) and adults emerged within one week ${ }^{(26)}$.

Table 3. Mortality of the pupae of Ae. aegypti developed from the eggs treated at $35^{\circ} \mathrm{C}$ in different exposure periods and control in an ambient condition of the laboratory (at $28 \pm 4^{\circ} \mathrm{C}$ and $80 \% \mathrm{RH})$.

\begin{tabular}{lccccc}
\hline $\begin{array}{l}\text { Exposure Total no. of } \\
\text { period } \\
\text { (hrs) }\end{array}$ & $\begin{array}{c}\text { larvae } \\
\text { pupated }\end{array}$ & $\begin{array}{c}\text { Total no. } \\
\text { of pupae } \\
\text { died }\end{array}$ & $\begin{array}{c}\text { Number of } \\
\text { pupae died } \\
(\text { Mean } \pm \text { SD) }\end{array}$ & $\begin{array}{c}\text { Mean pupal } \\
\text { mortality } \\
(\%)\end{array}$ & F value \\
\hline Control & 134 & 5 & $1.66 \pm 0.577$ & 3.32 & \\
0.5 & 110 & 14 & $4.66 \pm 2.516$ & 9.32 & \\
1 & 100 & 17 & $5.66 \pm 4.041$ & 11.32 & \\
2 & 100 & 18 & $6.00 \pm 4.358$ & 12.00 & 0.649446 \\
4 & 85 & 21 & $7.00 \pm 5.29$ & 14.00 & \\
8 & 77 & 15 & $5.00 \pm 3.464$ & 10.00 & \\
24 & 71 & 14 & $4.66 \pm 2.886$ & 9.32 & \\
\hline
\end{tabular}

Insignificant at $5 \%$ level $(\mathrm{F}=0.649446, \mathrm{p}>0.05)$.

Table 4. Mean duration of the larvae and pupae of Ae. aegypti obtained from the eggs treated at $35^{\circ} \mathrm{C}$ in different exposure periods and control in an ambient condition of the laboratory at $28 \pm 4^{\circ} \mathrm{C}$ and $80 \% \mathrm{RH}$.

\begin{tabular}{|c|c|c|c|c|c|c|c|c|}
\hline \multirow[t]{2}{*}{ Stage } & \multirow[t]{2}{*}{$\begin{array}{l}\text { Control } \\
\text { (hrs) }\end{array}$} & \multicolumn{6}{|c|}{$\begin{array}{c}\text { Exposure period in hours } \\
(\text { Mean } \pm S D)\end{array}$} & \multirow[t]{2}{*}{ F value } \\
\hline & & 0.5 & 1 & 2 & 4 & 8 & 24 & \\
\hline Larvae & $\begin{array}{l}114.6 \pm \\
3.34^{b}\end{array}$ & $\begin{array}{l}87.4 \pm \\
4.79^{\mathrm{b}}\end{array}$ & $\begin{array}{l}85.5 \pm \\
5.31^{\text {bd }}\end{array}$ & $\begin{array}{l}83.0 \pm \\
5.08^{\mathrm{bcd}}\end{array}$ & $\begin{array}{l}81.6 \pm \\
5.44^{\text {de }}\end{array}$ & $\begin{array}{l}80.5 \pm \\
7.46^{\mathrm{e}}\end{array}$ & $\begin{array}{l}76.4 \pm \\
1.075^{\mathrm{a}}\end{array}$ & $64.4427^{*}$ \\
\hline Pupae & $\begin{array}{l}41.8 \pm \\
0.966^{\mathrm{ab}}\end{array}$ & $\begin{array}{r}40.4 \pm \\
1.349^{\mathrm{b}}\end{array}$ & $\begin{array}{l}39.6 \pm \\
1.37 \mathrm{~b}\end{array}$ & $\begin{array}{l}38.9^{ \pm} \\
1.791^{\mathrm{c}}\end{array}$ & $\begin{array}{l}37.1 \pm \\
2.299 \mathrm{~d}\end{array}$ & $\begin{array}{l}35.2 \pm \\
2.923^{e}\end{array}$ & $\begin{array}{l}33.1 \pm \\
0.421^{\mathrm{a}}\end{array}$ & $30.0153^{*}$ \\
\hline
\end{tabular}

Significant at $5 \%$ level $(F=64.4427, p<0.05$ for larvae and $F=30.0153, p<0.05$ for pupae); same letters in the column show insignificance at $5 \%$ level in DMRT.

The time between pupation and emergence of Ae. aegypti at $23-27^{\circ} \mathrm{C}$ was 45 hours for males and 60 hours for females, and the mean periods of the mosquito from eclosion to pupation at $27^{\circ} \mathrm{C}$ was 6.4 days ( 154 hours) and seven days for this period at $23-26^{\circ} \mathrm{C}$, respectively ${ }^{(27)}$. The larval developmental time of Ae. albopictus from egg hatching to 
pupation was inversely correlated with temperature, lasting seven days at $32^{\circ} \mathrm{C}$ and the duration of pupal period varied between two and three days at that temperature(28). This indicates that with the decrease of temperature, the larval and pupal period becomes prolonged. The larval and pupal duration of Ae. albopictus depends also on the nature of containers in which they are developing; the total time from egg hatching to adult emergence in tree hole, bamboo stump and auto tyre in a temperature range between 18 and $22^{\circ} \mathrm{C}$ were $19.6,27.3$ and 37.5 days, respectively ${ }^{(29)}$.

The lengths of the $2^{\text {nd }}, 3^{\text {rd }}$ and $4^{\text {th }}$ instar larvae of $A e$. aegypti at $35^{\circ} \mathrm{C}$ for various exposure periods and control are shown in Table 5. Significant differences in length among different exposure periods and control were observed in the $2^{\text {nd }}$ instar larvae $(\mathrm{F}=$ 4.314, $\mathrm{p}<0.05)$ and $3^{\text {rd }}$ instar $(\mathrm{F}=3.786, \mathrm{p}<0.05)$. The lengths of the $2^{\text {nd }}$ and $3^{\text {rd }}$ instar larvae were the highest (viz., 4.52 and $6.46 \mathrm{~mm}$, respectively) in control. The $3^{\text {rd }}$ and $4^{\text {th }}$ instar larvae developed from the eggs treated at $35^{\circ} \mathrm{C}$ in different exposure periods showed no significant difference in mean body length among the exposure periods. High temperature showed insignificant $(F=1.138424, \mathrm{p}>0.05)$ effect on the length of the $4^{\text {th }}$ instar larvae in different exposure periods and control.

Table 5. Mean length $(\mathrm{mm})$ of $2^{\text {nd }}, 3^{\text {rd }}$ and $4^{\text {th }}$ instar larvae of Ae. aegypti from the eggs treated at $35^{\circ} \mathrm{C}$ in different exposure periods and control in an ambient condition of the laboratory at $28 \pm 4^{\circ} \mathrm{C}$ and $80 \%$ RH.

\begin{tabular}{llllllll}
\hline \multirow{2}{*}{$\begin{array}{l}\text { Larval } \\
\text { instar }\end{array}$} & Control & \multicolumn{5}{c}{ Mean larval length (mm) in exposure period (hrs) } \\
\cline { 3 - 8 } & & 0.5 & 1 & 2 & 4 & 8 & 24 \\
\hline $2^{\text {nd }}$ & $4.518 \pm$ & $3.845 \pm$ & $3.65 \pm$ & $3.88 \pm$ & $3.855 \pm$ & $3.625 \pm$ & $3.615 \pm$ \\
& $0.587^{\mathrm{b}}$ & $0.237^{\mathrm{a}}$ & $0.579 \mathrm{~b}$ & $0.475^{\mathrm{b}}$ & $0.484^{\mathrm{b}}$ & $0.457^{\mathrm{b}}$ & $0.442^{\mathrm{b}}$ \\
$3^{\text {rd }}$ & $6.455 \pm$ & $5.74 \pm$ & $5.915 \pm$ & $5.935 \pm$ & $5.715 \pm$ & $5.635 \pm$ & $5.575 \pm$ \\
& $0.613^{\mathrm{a}}$ & $0.445^{\mathrm{b}}$ & $0.464^{\mathrm{b}}$ & $0.393^{\mathrm{b}}$ & $0.455^{\mathrm{b}}$ & $0.498^{\mathrm{b}}$ & $0.481^{\mathrm{b}}$ \\
& $7.616 \pm$ & $7.62 \pm$ & $7.52 \pm$ & $7.31 \pm$ & $7.35 \pm$ & $7.37 \pm$ & $7.13 \pm$ \\
$4^{\text {th }}$ & 0.557 & 0.534 & 0.493 & 0.471 & 0.522 & 0.527 & 0.506 \\
& & &
\end{tabular}

Significant at $5 \%$ level $\left(\mathrm{F}=4.314312^{*}, \mathrm{p}<0.05\right.$ for $2^{\text {nd }}$ instar larvae; $\mathrm{F}=3.785768^{*}, \mathrm{p}<0.05$ for 3rd instar larvae); and insignificant at $5 \%$ level $\left(\mathrm{F}=1.138424, \mathrm{p}>0.05\right.$ for $4^{\text {th }}$ instar larvae,). Same letters in the columns show insignificance at $5 \%$ level in DMRT.

The transverse diameter of the head capsules of $1^{\text {st }}$ and $4^{\text {th }}$ instar larvae was significant $(\mathrm{F}=6.6512, \mathrm{p}<0.05$ and $\mathrm{F}=4.5209, \mathrm{p}<0.05$, respectively $)$, but ${ }^{\text {nd }} 2^{\text {nd }}$ and $3^{\text {rd }}$ instars showed insignificance $(\mathrm{F}=0.353, \mathrm{p}>0.05$ and $\mathrm{F}=0.17, \mathrm{p}>0.05$, respectively) (Table 6). 
Temperatures ranging from $15-31^{\circ} \mathrm{C}$ significantly affect the size of head capsule widths of the larval instars of Ae. albopictus and Ae. triseriatus in laboratory(30).

Table 6. Mean diameter (mm) of the head capsule of all four larval instars of Ae. aegypti obtained from the eggs treated at $35^{\circ} \mathrm{C}$ in different exposure periods and control in an ambient condition of the laboratory at $28 \pm 4^{\circ} \mathrm{C}$ and $80 \% \mathrm{RH}$.

\begin{tabular}{llllllll}
\hline \multirow{2}{*}{$\begin{array}{l}\text { Larval } \\
\text { instar }\end{array}$} & Control & \multicolumn{5}{c}{ Mean diameter $(\mathrm{mm})$ of head capsule in exposure period (hrs) } \\
\cline { 3 - 7 } & & 0.5 & 1 & 2 & 4 & 8 & 24 \\
\hline $1^{\text {st }}$ & $0.336 \pm$ & $0.332 \pm$ & $0.302 \pm$ & $0.293 \pm$ & $0.285 \pm$ & $0.275 \pm$ & $0.243 \pm$ \\
& $0.350^{\mathrm{a}}$ & $0.0373^{\mathrm{ab}}$ & $0.041^{\mathrm{bc}}$ & $0.056^{\mathrm{bc}}$ & $0.0368^{\mathrm{c}}$ & $0.0263^{\mathrm{c}}$ & $0.018^{\mathrm{c}}$ \\
$2^{\text {nd }}$ & $0.476 \pm$ & $0.456 \pm$ & $0.467 \pm$ & $0.45 \pm$ & $0.436 \pm$ & $0.417 \pm$ & $0.387 \pm$ \\
& 0.127 & 0.146 & 0.182 & 0.199 & 0.196 & 0.167 & 0.108 \\
$3^{\text {rd }}$ & $0.695 \pm$ & $0.684 \pm$ & $0.684 \pm$ & $0.69 \pm$ & $0.681 \pm$ & $0.672 \pm$ & $0.644 \pm$ \\
& 0.12 & 0.135 & 0.131 & 0.141 & 0.132 & 0.13 & 0.11 \\
$4^{\text {th }}$ & $0.907 \pm$ & $0.871 \pm$ & $0.853 \pm$ & $0.811 \pm$ & $0.77 \pm$ & $0.745 \pm$ & $0.723 \pm$ \\
& $0.039^{\mathrm{a}}$ & $0.041^{\mathrm{ab}}$ & $0.053^{\mathrm{abc}}$ & $0.156^{\mathrm{bcd}}$ & $0.141^{\mathrm{cd}}$ & $0.123^{\mathrm{d}}$ & $0.085^{\mathrm{d}}$ \\
\hline
\end{tabular}

Significant at $5 \%$ level $\left(\mathrm{F}=6.6512^{*}, \mathrm{p}<0.05\right.$ and $\mathrm{F}=4.5209^{*}, \mathrm{p}<0.05$, for $1^{\text {st }}$ and $4^{\text {th }}$ instar larvae, respectively; insignificance $\left(\mathrm{F}=0.353, \mathrm{p}>0.05\right.$ and $\mathrm{F}=0.17, \mathrm{p}>0.05$ for $2^{\text {nd }}$ and $3^{\text {rd }}$ instar larvae, respectively). Same letters in the row show insignificance at $5 \%$ level in DMRT.

The length of the cephalothorax of the pupae of Ae. aegypti is shown in Table 7. The length of the cephalothorax of the pupae developed from the eggs treated with high temperature and different exposure periods showed significance at $5 \%$ level ( $F=2.343$, $\mathrm{p}<0.05)$. It was also seen that the eight and 24 hours exposure periods showed similarities with control, but half an hour, one, two, four hour exposures of high temperature had no effect among them. However, they differed from the control.

The body length of adult males and females is also shown in Table 7. High temperature showed no effect $(\mathrm{F}=0.353, \mathrm{p}>0.05$ for the males and $\mathrm{F}=0.614, \mathrm{p}>0.05$ for the females) on the body length of adult males and females Ae. aegypti emerged from the eggs treated with high temperature at $35^{\circ} \mathrm{C}$. Adult size increased as temperature decreased.

The temperature at $35^{\circ} \mathrm{C}$ and different exposures have negative impacts on mosquito development as these have been observed in egg hatching, larval and pupal mortality, duration of larval and pupal periods, morphometry of larvae, pupae and adults, and fecundity of Ae. Aegypti in the laboratory. In a different approach other than the above aspects, Alto and Juliano ${ }^{(31)}$ observed that the populations of Ae. albopictus at $26^{\circ} \mathrm{C}$ had greater intrinsic rates of increase and lower asymptotic densities than populations at 22 and $24^{\circ} \mathrm{C}$; the populations at high temperatures initially had greater daily per capita 
emergence rates, and steeper declines in per capita emergence rate as density increased over the course of the experiment. They also observed that there was no temperature effect on the size of adult females nor on the per capita daily mortality rate of adults. In concluding remarks they said that in regions with relatively high summer temperatures, the populations of Ae. albopictus are likely to have high rates of population growth with adult populations peaking early in the season and these populations may attain relatively low peak densities of adults; whereas, the populations occurring in regions with low summer temperatures are likely to experience slow, steady production of adults throughout the season with population size peaking later in the season, and may attain higher peak densities of adults. They also opined that high temperature conditions, associated with climate change, might increase the rate of spread of Ae. albopictus by increasing rates of increase and by enhancing colonization due to rapid population growth. As the two mosquito species, Ae. aegypti and Ae. Albopictus, are very close, we may therefore expect the similar effects on Ae. aegypti as well which may be worth trying to investigate in the laboratory and field conditions in the country.

Table 7. Mean cephalothoracic length of pupae and adult body length of Ae. aegypti obtained from the eggs treated at $35^{\circ} \mathrm{C}$ in different exposure periods and control in an ambient condition of the laboratory at $28 \pm 4^{\circ} \mathrm{C}$ and $80 \% \mathrm{RH}$.

\begin{tabular}{|c|c|c|c|c|c|c|c|}
\hline \multirow{2}{*}{$\begin{array}{l}\text { Pupa and } \\
\text { adult }\end{array}$} & \multirow{2}{*}{ Control } & \multicolumn{6}{|c|}{ Mean length (mm) in exposure period (hrs) } \\
\hline & & 0.5 & 1 & 2 & 4 & 8 & 24 \\
\hline $\begin{array}{l}\text { Cephalothorax } \\
(\mathrm{mm})\end{array}$ & $\begin{array}{l}1.907 \pm \\
0.317^{\mathrm{a}}\end{array}$ & $\begin{array}{l}1.49 \pm \\
0.346^{\mathrm{b}}\end{array}$ & $\begin{array}{l}1.605 \pm \\
0.28^{b}\end{array}$ & $\begin{array}{l}1.6 \pm \\
0.3^{\mathrm{b}}\end{array}$ & $\begin{array}{l}1.505 \pm \\
0.345^{\mathrm{b}}\end{array}$ & $\begin{array}{l}1.7 \pm \\
0.217^{\mathrm{ab}}\end{array}$ & $\begin{array}{l}1.715 \pm \\
0.246^{\mathrm{ab}}\end{array}$ \\
\hline $\begin{array}{l}\text { Male body } \\
\text { length (mm) }\end{array}$ & $\begin{array}{l}3.00 \pm \\
0.349\end{array}$ & $\begin{array}{l}2.98 \pm \\
0.332\end{array}$ & $\begin{array}{l}2.98 \pm \\
0.339\end{array}$ & $\begin{array}{l}2.97 \pm \\
0.34\end{array}$ & $\begin{array}{l}2.97 \pm \\
0.34\end{array}$ & $\begin{array}{l}2.94 \pm \\
0.333\end{array}$ & $\begin{array}{l}2.9 \pm \\
0.362\end{array}$ \\
\hline $\begin{array}{l}\text { Female body } \\
\text { length (mm) }\end{array}$ & $\begin{array}{l}3.51 \pm \\
0.251\end{array}$ & $\begin{array}{l}3.50 \pm \\
0.258\end{array}$ & $\begin{array}{l}3.46 \pm \\
0.231\end{array}$ & $\begin{array}{l}3.44 \pm \\
0.231\end{array}$ & $\begin{array}{l}3.41 \pm \\
0.242\end{array}$ & $\begin{array}{l}3.38 \pm \\
0.248\end{array}$ & $\begin{array}{l}3.33 \pm \\
0.346\end{array}$ \\
\hline
\end{tabular}

Significant at $5 \%$ level $\left(\mathrm{F}=2.343166^{*}, \mathrm{p}<0.05\right.$ for pupal cephalothoraxes; insignificance $(\mathrm{F}=0.353$, $\mathrm{p}>0.05$ and $\mathrm{F}=0.614, \mathrm{p}>0.05$ for adult males and females, respectively). Same letters in the row show insignificance at $5 \%$ level in DMRT.

Man has been altering the atmosphere through its various activities. Continuous increase in the concentration of various green house gases, such as carbon dioxide, carbon monoxide, methane, various oxides of nitrogen, and the chloro-floro-carbons (CFCs), which absorb infrared radiation in the spectral bands where there are gaps in the carbon dioxide and water spectra, thus closing the atmospheric window leading to an increased radiation absorption by the atmosphere, and its retention increases the temperature of the earth; as a consequence, large-scale changes in the temperature- 
climate pattern of the earth-atmosphere system are expected ${ }^{(32)}$. Since $40 \%$ of the global warming is caused by carbon dioxide, as the concentration of the gas in the atmosphere rises, increased radiation trapping will lead to an increased greenhouse effect and consequent global warming; as the temperature rises, more water will evaporate and pass into the atmosphere; water vapour is even more effective than carbon dioxide in preventing the long-wave radiations of the earth from escaping(32). Thus, the effects of man's interference with the carbon cycle through fossil fuel consumption, deforestation, agricultural practices, industrial emission and nuclear testing has already started to show an impact on the biosphere(32).

In conclusion, from the above discussion it is very much indicative that temperature changes have influential impacts on mosquito life and its population dynamics. To know more about the long term effects of temperature (global warming) on the mosquito population of Bangladesh, both laboratory and field experiments should be initiated, as further attempts, on the sustenance of the effects of high temperature on the subsequent generations of the mosquito. If possible, both genetic and ecological approaches may be included in this focused area.

\section{Referrences}

1. Ameen, M and M Moizuddin 1972. Bionomics of the common mosquitoes of Dacca. J. nat. Hist. 6: 21

2. Ameen, M and M Moizuddin 1973. Bionomics of the common mosquitoes of Dacca. J. nat. Hist. 7: 1- 21.

3. Khan NI 1980. Studies on the morphology and taxonomy of the larval pupal stages of six common culicine mosquitoes of Dhaka city. M.Sc. thesis, Department of Zoology, University of Dhaka. iv + pp. 159.

4. Ameen M, I Hossain and MDH Khan 1982. Resting behaviour, biting activity pattern and host preference of the common mosquitoes of Dhaka city. Bangladeh J. Zool. 10(1): 35-48.

5. Ameen, M and M Moizuddin 1973. The duration of the various developmental stages of Culex qinquefasciatus Wied. (Diptera: Culicidae) in Dhaka, Bangladesh, Bangladesh J. Zool. 1(1): 11-12.

6. Huda KMN and MM Rahman 1976. Mosquito control potential of some indigenous fishes in Bangladesh. Bangladesh J. Zool. 10(2): 145-147.

7. Ahmed TU, GP Joshi, RU Ahmed, ZU Dewan, MN Begum, S Akhter and ME Khoda 1989. Study on seasonal density of common mosquitoes in jungle area of Modhupur, Tangail. Bangladesh J. Zool. 4: 1-14.

8. Simard F, E Nchoutpouen, JC Toto, and D Fontenille 2005. Geographic Distribution and Breeding Site Preference of Aedes albopictus and Aedes aegypti (Diptera: Culicidae) in Cameroon, Central Africa. J. Med. Entomol. pp. 726-731.

9. Kumer A, VP Sharma, D Thavaselvam and PK Sumodan 1995. Control of Anopheles stephensi breeding in construction sites and abandoned overhead tanks with Bacillus thuringiensis var. israelensis. J. Am. Mosq. Cont. Assoc. 11(1): 86-89. 
10. Wigglesworth VB 1965. The principles of Insect Physiology. (6 $6^{\text {th }}$ Ed., revised), Methuen and Co. Ltd., London viii + pp. 741.

11. Davidson J 1944. On the relationship between temperature and rate of development of insects at constant temperatures. J. Anim. Ecol. 13: 29-38.

12. Mellanby K 1932. The influence of atmospheric humidity on the thermal death point of a number of insects. J. Exp. Biol. 9: 22-31.

13. Hagstrum DW and EB Workman 1971. Interaction of temperature and feeding rate in determining the rate of development of larval Culex tarsalis (Diptera: Culicidae) Ann. Ent. Soc. Am. 64(3): 668-671.

14. Nayar JK 1968. Effects of larval and pupal environmental factors on biological status of adults at emergence in Aedes tritaeniorhynchus (Weid.) Bull. Ent. Res. 58: 811-827.

15. Dakshinamurty S and MID Sharma 1951. The temperature preferences of mosquitoes. Indian J. Malariol. Calcutta 5 : 221-227.

16. Service MW 1970. Studies on the biology and taxonomy of Aedes (Stegomyia) vittatus (Biot) (Diptera: Culicidae) in Northern Nigeria. Trans. Roy. Ent. Soc. London 122: 101-143.

17. Christopher SR 1960. Aedes aegypti (L.), the yellow fever mosquito: its life history, bionomics and structure. Cambridge Univ. Press, London, xii + pp. 739.

18. Abbot WS 1925. A method of computing the effectiveness of an insecticide. J. econ. Entomol. 18: 265-267.

19. Alto BW and Julian SA 2001. Precipitation and temperature effects on population of Aedes albopictus (Diptera: Culicidae): Implication for Range Expansion. Med. Entomol. Zool. 38(5): 646-656.

20. Bacot AW 1916. Report of the Yellow Fever Commission. London 3: 234-235.

21. Bar-zeev M 1957. The effect of extreme temperature on different stages of Aedes aegypti (L.). Bull. Ent. Res. 48: 593-599.

22. Francis E 1907. Observations on the life cycle of Stegomyia calopus. Pub. Hlth Rep. Wash. 22: 381383.

23. Newstead R and HW Thomas 1910. The mosquitoes of the Amazon Region. Ann. Trop. Med. Parasit. 4: 141-150.

24. Marchoux E, A Salimbeni and PL Simond 1903. La fievre jaune. Repport de la Mission Francaise. Ann. Inst. Pasteur. 17: 665-731.

25. Lyimo EO, W Takken and JC Koella 1992. Effect of rearing temperature and larval density on larval survival, age at pupation, and adult size of Anopheles gambiae. Entomol. Expt. Appl. 63(3): 265-271.

26. Luduena Almeida FF and DE Gorla 1995. The biology of Aedes (Ochlerotatus) albifasciatus Macquart, 1838 (Diptera: Culicidae) in Central Argentina. Mem. Inst. Cruz. Rio de Janeirol. 90(4): 463-468.

27. Shannon RC and P Putnam 1934. The biology of Stegomyia under laboratory conditions. I. The analysis of factors which influence larval development. Proc. Ent. Soc. Wash. 36: 85-216.

28. Briegel H and SE Timmermann 2001. Aedes albopictus (Diptera: Culicidae): Physiological Aspects of Development and Reproduction. J. Med. Entomol. pp. 566-571. 
29. Gomes AC, SLD Gotlieb, CCA Marques, MB Paula and GRAM Marques 2001. Duration of larval and pupal development stages of Aedes albopictus in natural and artificial containers. Rev. Saude. Publca. 29(1): (downloaded from the internet).

30. Teng HJ and CS Apperson 1996. Identification of larval instar of Aedes albopictus (Skuse) and Aedes triseriatus (Say) (Diptera: Culicidae) based on head capsule size. J. Vector Ecol. 21: 186-191.

31. Alto BW and SA Juliano 2001. Temperature effects on the Dynamics of Aedes albopictus (Diptera: Culicidae) populations in the laboratory. J. Med. Entomol. 38(4): 548-556.

32. Mukherjee B 1996. Environmental biology. Tata McGraw-Hill Publishing Co. Ltd., New Delhi, pp. 691.

(Manuscript received on 17 October, 2011; revised on 13 January, 2013) 